merchant service to obtain and bring home information that would be useful to science, and might, by means of lectures and otherwise, foster a scientific spirit among our commercial population. Much good is done in this way, we believe, by the societies of Marseilles, Bordeaux, and Lyons. Two new geographical societies have, we learn, been established in France, at Metz and Montpellier. The French are evidently doing their best to remove the reproach so frequently cast at them, of being more ignorant of geography than even the English.

THAT the Continental societies go in for earnest work is evident from the weighty journals published by most of them. The Mittheilungen of the Hamburg Society for 1876-77, for example, is a thick volume of 400 pages, containing a number of papers of considerable scientific value. Besides several papers on Central and South America, there is a long series of letters by Dr. Pfund, filling nearly half the volume, written during his travels in Kordofan and Darfur, along with Colonel Prout, of the Egyptian staff. Other African papers are by Dr. Paul Ascherson on his travels in the Lybian desert in I876, and one of much value by Herr Fischer, on the present condition of the Galla Country. In the Deutsche Geographische Blätter, the organ of the Bremen Society, Dr. Oskar Lenz discusses at length the trade conditions in Equatorial West Africa, with special reference to Stanley's discoveries; Dr. Lenz does not believe that the Ogovai is connected with the Congo. Mr. W. H. Dall is contributing to this journal a series of papers on his own and other recent researches in the Aleutian Islands, while Dr. A. Ziegler has an interesting paper on Regiomontanus and Martin Behaim. Turning to Italy the energetic Roman Society has begun the publication (apart from their always interesting Bolletino) of Memorie, containing at length the most important papers read at the Society's meetings. The first part contains a lecture by the president, Signor Cristifero Negri, on scientific geography, which shows what has more than once been said, that geography is really the meeting-place of all the sciences. Then there is a paper on the geographical distribution of camels, by Prof. Luigi Lombardini, and a well-arranged series of instructions to explorers by various specialists, edited by Signor A. Issel. Nor must we forget the American Society, with its seat at New York, and which is the medium for a good deal of valuable information that might not otherwise reach the light of day. Chief-Justice Daly's presidential address always contains an admirable and exhaustive summary of the year's work ; and this year it is quite as full and interesting as usual, nothing in the domain of geography of any importance remaining untouched, special prominence being of course given to the various surveys of the United States. Thus it will be seen, that under the name of geography, much varied and really valuable work is being done, and that dilletanteism has really but a small place in it, at least abroad.

AN expedition, comprising twenty-five miners and others, has started for New Guinea. This news is telegraphed from Sydney, and we earnestly hope that the expedition is under proper direction, both for the sake of the natives, who have so far been friendly to white men, and for the sake of further scientific discovery.

\section{THE TRANSIT OF MERCURY}

$T$ HE weather on Monday was so unfavourable that the observations of this interesting phenomenon were mostly unfortunate in England. In France some valuable observations seem to have been made. Our Paris Correspondent writes that the observations taken by $M$. Janssen at Meudon Observatory were wonderfully successful considering the state of the atmosphere. He was able to make use of spectrum analysis in order to deter- mine the composition of Mercury's atmosphere. He was able to see Mercury before it had begun to make its first entrance on the disc. This observation is a confirmation of the phenomena observed in 1874 at Yokohama on the occasion of the Transit of Venus. Two photographs are excellent, and will lead to a determination of the diameter of the planet. At the Paris Observatory the transit was also seen.

When Capt. Mouchez saw Mercury the disc had been indented to the extent of $2^{\prime \prime}$ of degree, about ${ }_{6}^{\prime}$ th diameter of Mercury. When it was seen by the brothers Henry it was half on the disc. The difference of time is about $10^{\prime}$ later at the National Observatory. The brothers Henry also saw the interior contact at about $3 \mathrm{~h} .23 \mathrm{~m}$. and some seconds. The exact time cannot be given yet. The cortact was decidedly bad owing to the clouds.

At Algiers and Bordeaux the observations were bad. At Ogden, Utah, United States, the delegates sent by the French Government, M. André, of Lyons, and M. Angot, of Paris, obtained seventy-eight photographs of the transit. Satisfactory observations and photographs of the transit were taken at the Government Observatories at Washington and West Point, U.S.

Mr. J. J. Cole writes to the Times from Mayland, Sutton, Surrey, that the sun was clear from 3.5 to 3.25 , and the whole ingress was steadily observed with a refractor of 6 inch aperture and three others smaller. The Greenwich mean times of external and internal contact were taken, and were confirmed by $\mathrm{Mr}$. Bawtree near with unexpectedly small differences.

At Aberdeen the transit was observed by Lord Lindsay, Mr. Ranyard, Dr. Copeland, Mr. Carpenter; and Herr Lohse, and photographed by Mr. Davis. A thin cloud covered the sun at the time of first contact. No ring of of light was seen round the part of the planet off the sun's disc. External contact was observed spectroscopically by Lord Lindsay, who detected the approach of the planet by the eclipse of the $C$ line thirteen seconds before its limb encroached upon the continuous spectrum of the photosphere. Mr. Ranyard observed the continuous spectrum below $C$ line, but saw no trace of the planet until it was on the sun's disc. No change in the solar spectrum was observed at the limb of the planet. Dr. Copeland, Mr. Carpenter, and Herr Lohse obtained both contacts and measures of diameter.

Mr. C. G. Talmage writes as follows to the Times from Mr. Barclay's Observatory, Leyton, Essex :-

"Owing to the prevalence of clouds the times of external and internal contact at ingress were not observed here. The first view I obtained was at 3.43, when Mercury had advanced some considerable distance on the sun's disc. The duration of clear sky was then so short that there was not sufficient time to obtain micrometrical measures of distance from the sun's limb. For about eight or ten seconds the sky was absolutely clear, arrd then I noticed that Mercury was surrounded by a bright ring, darkening off to the periphery, which was exceedingly well defined. The distance between the limb of Mercury and periphery of ring was about two-thirds of the planet"s diameter. I used the full aperture of ten inches, with a diagonal power of eighty."

\section{DE CAILLETET'S APPARATUS}

WE have already (vol. xvii. p. 265) spoken at length of M. Cailletet's method of liquefying the last of the gases, and at the same time we referred to the fact that students of science in France had not been forgotten by the accomplished experimenter. We described briefly a portion of an apparatus for use in laboratories for this experiment, and are now able to give an illustration of the complete laboratory apparatus as manufactured by Ducretet and Co., of Paris. The figure shows the apparatus one-eighth the size of reality. 
To work this apparatus it is necessary to take off the liquefying tube $\mathrm{T}$ and all the pieces of the upper part; also the lateral screw $\mathrm{E}^{\prime}$ and its tube $\mathrm{A}^{\prime}$; then, after having screwed on to the joint $\mathrm{R}$ the piece $\mathrm{N}$, which serves as a stop-valve, the mercury should be turned dry and quite pure, into the wrought-iron reservoir $B$, up to the level of the edges $\mathrm{N} \mathrm{N}^{\prime}$. The sides of this iron reservoir are very resistant and are able to support strong pressures.

The tube $\mathrm{T}$ having been filled with gas for liquefaction, it is gently forced into the mercury of the reservoir $\mathrm{B}$; the part $\mathrm{N}$ being taken out, the mercury which flows out is collected. When the tube A rests on the leather of the bottom of the length of the reservoir, the screw $E^{\prime}$ is re-screwed very tightly. The apparatus is inclined a little to get rid of the excess of mercury, in order that its level may remain below the lateral hole by which the pressure is introduced.

The support $S$ with refrigerating envelope $M$ is then re-screwed on the upper part of the ajutage $\mathrm{A}$; it rests

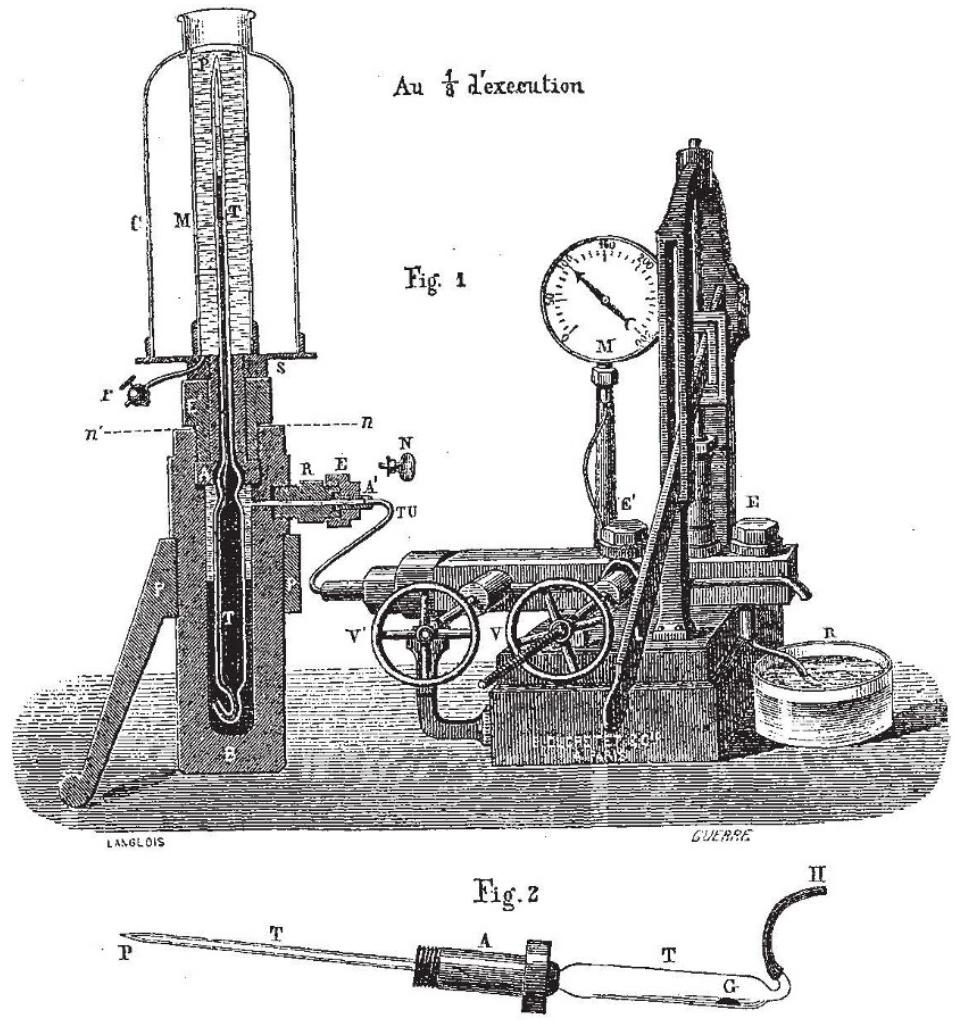

upon leather. The safety-bell-jar $\mathrm{C}$ is movable; it is intended to stop the pieces of glass should the tube $\mathrm{T}$ be broken. The stop-cock $r$ lets the water flow from the envelope $M$. The lateral screw with the tube $A^{\prime}$ is refixed, to which is soldered the small metallic tube $\mathrm{TV}$, by which pressure is introduced.

The hydraulic pump, which Ducretet and Co. have constructed specially for this apparatus, is for the purpose of compressing water about the mercury contained in the reservoir. The two valves $\mathrm{E} \mathrm{E}^{\prime}$ may be introduced by the orifices closed by the screws $\mathrm{E} \mathrm{E}^{\prime}$; the valves may be thus tested and easily changed without undoing any

\section{NOTES}

ONE of the most effective methods of acquiring a headache is a good round of sightseeing, especially in a museum, collection, or picture-gallery; it is quite a comfort to get among a collection of any kind, the sight or catalogue of which does not make one ill by anticipation. Happily the headachy feature is generally absent from the collection of objects exhibited at the Royal Society conversazioni, and in this respect and because of its great interest, the collection brought together last Wednesday week was quite a model. Prof. Snellen's two modes of testing for colour-blindness ought to have been the first thing looked at, because then the guests would have been in a position to estimate the value of their observations. The inspection caused much part. The reservoir of water $\mathrm{R}$ is placed outside; it is then easily seen to and kept full.

Before setting the hydraulic pump to work, we withdraw as completely as possible the screw-plunger piston $\mathrm{v}$ by moving the fly-wheel. The action of the lever $I$ enables us to obtain easily a pressure of 200 atmospheres. This pressure may then be increased by the gentle introduction of the plunger-piston $\mathrm{v}$. The liquefying tube $\mathrm{T}$ is of thick glass; it has a resistance of about 400 atmospheres, but it is better not to exceed a pressure of 300 atmospheres. The second screw $\mathrm{V}^{\prime}$ is intended to produce expansion. 